\title{
O ETHOS DA CONFIANÇA NA PESQUISA CARTOGRÁFICA: EXPERIÊNCIA COMPARTILHADA E AUMENTO DA POTÊNCIA DE AGIR
}

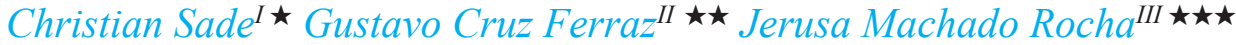 \\ ${ }^{I}$ Universidade Salgado de Oliveira, Niterói, RJ, Brasil \\ ${ }^{I I}$ Faculdade Salesiana Maria Auxiliadora, Macaé, RJ - Brasil \\ ${ }^{I I I}$ Universidade Federal do Rio de Janeiro, Rio de Janeiro, RJ - Brasil
}

\begin{abstract}
Resumo
Este texto discute as implicações metodológicas da confiança como um ethos na pesquisa cartográfica. A partir de autores como William James, Daniel Stern, Suely Rolnik e Vinciane Despret, definimos a confiança no entrelaçamento das noções de engajamento e indeterminação. A confiança nos dispõe a agir com base em um plano da experiência anterior à determinação de si e do mundo, o que contribui para a criação coletiva e participativa de conhecimento. A questão da constituição e do manejo dos vínculos no processo de pesquisa é pensada como um regime de contratação. Uma vez que na cartografia a produção de conhecimento é indissociável da construção de novas condições de existência, a aposta é de que a confiança na experiência implica a promoção de uma experiência compartilhada que amplia a potência de agir.

Palavras-chave: metodologia; método da cartografia; confiança.

\section{THE ETHOS OF TRUST IN CARTOGRAPHIC RESEARCH:} SHARED EXPERIENCE AND RAISE OF THE POWER OF ACTING
\end{abstract}

\begin{abstract}
The following text discusses the methodological implications of trust as an ethos in cartographic research. Based on authors such as William James, Daniel Stern, Sueli Rolnik and Vinciane Despret, we define trust in the interlacing of concepts such as engagement and indeterminacy. Trust predisposes us to act based on

^ Psicólogo. Doutor em Psicologia pela Universidade Federal do Rio de Janeiro; atualmente é professor do curso de Psicologia da Universidade Salgado de Oliveira (UNIVERSO) e atua em projeto de pesquisa do departamento de Psicologia da Universidade Federal Fluminense.

E-mail: christiansadevas@yahoo.com.br

$\star \star$ Psicólogo. Doutor em Psicologia pela Universidade Federal do Rio de Janeiro. Realizou Estágio de Doutorado no Exterior como bolsista CAPES na Universidade Paris VIII, França. Realizou PósDoutorado (bolsa CNPq) no Programa de Pós-Graudação em Psicologia da Universidade Federal Fluminense. Professor no curso de Psicologia da Faculdade Salesiana Maria Auxiliadora, Macaé. E-mail: gusferraz@yahoo.com.br

$\star \star \star$ Psicóloga. Doutorado em Psicologia pela Universidade Federal do Rio de Janeiro. Atualmente exerce a função de Psicóloga/Pesquisadora na Universidade Federal do Rio de Janeiro (DPA/UFRJ), supervisionando estagiários do curso de formação em psicologia. Participa do grupo de pesquisa em Cognição e subjetividade, e do núcleo de pesquisa PesquisarCom desenvolvido no Instituto Benjamin Constant. Endereço: Universidade Federal do Rio de Janeiro, Instituto de Psicologia, Divisão de Psicologia Aplicada. Avenida Pasteur, 250 Fundos. Botafogo. Rio de Janeiro, RJ - Brasil. CEP: 22290-240.

E-mail: jerusa@psicologia.ufrj.br
\end{abstract}


a former experience plan, earlier to determination of self and of the world, which contributes to the collective and participatory creation of knowledge. The construction issue and handling of bonds in the research process is conceived as an engagement regimen. Given that in the cartography knowledge production is inseparable from the construction of new existence conditions, the bet relies on trusting the experience implicating the promotion of a shared experience that expands the power of acting.

Keywords: methodology ;cartographic method; trust.

Acreditar no mundo é o que mais nos falta; nós perdemos completamente o mundo, nos desapossaram dele. Acreditar no mundo significa principalmente suscitar acontecimentos, mesmo pequenos, que escapem ao controle, ou engendrar novos espaços-tempos, mesmo de superfície ou volumes reduzidos. (DELEUZE, 1992, p.18).

Em uma pesquisa com cegos, realizada no Instituto Benjamin Constant, um participante, convidado para uma entrevista sobre sonhos e imagens mentais, mostrou-se particularmente interessado em ser entrevistado. ${ }^{1}$ Afirmou, na ocasião, que não gostava de participar de pesquisas em que era submetido a questionários com perguntas que ele normalmente não sabia responder. Segundo sua avaliação, tais questionários eram concebidos tendo como parâmetro o funcionamento cognitivo do vidente. O participante concluiu que muitas vezes os pesquisadores não se interessam pela experiência de ser cego, pois os questionários não fazem as perguntas adequadas para o entendimento do seu modo singular de perceber e pensar. Trata-se de testes voltados para a apreensão de deficiências, falhas e déficits. Já a entrevista proposta naquele momento, voltada para o tema dos sonhos e realizada no contexto da cartografia, acolhia a experiência da cegueira, ao permitir que ele falasse a partir dela. A confiança na pesquisa contribuía para o seu engajamento. Esse é um caso analisador da qualidade da relação entre o pesquisador e os participantes, e que ressalta o aspecto ético-político da prática de pesquisa.

Segundo Stengers (1993) e Despret (2004), para a pesquisa que lida com seres que nenhum expediente pode torná-los indiferentes ao fato de que são interrogados é incontornável a discussão em torno dos diferentes sentidos que assume o processo de investigação. Tendo em vista o caráter performativo dos dispositivos utilizados na pesquisa cartográfica (PASSOS; BENEVIDES DE BARROS, 2009; PASSOS; EIRADO, 2009), a produção desses diferentes sentidos pressupõe um plano de implicação que entrecruza os diversos atores no processo. Esse caráter implicado da produção de conhecimento na cartografia nos convoca a pôr em questão os seus efeitos de produção de subjetividade.

As pesquisas de campo estão frequentemente voltadas para grupos específicos, os quais apresentam experiências singulares, muitas vezes marcadas por muitas dificuldades, e até mesmo por sofrimento. Numa investigação cartográfica, conhecer tais experiências equivale a transformá-las, o que coloca o desafio 
de pensar qual é o rumo a ser dado à intervenção e como fazer. Os sentidos adquiridos pela pesquisa dependem dos modos como o seu processo é incorporado, isto é, dos modos de sentir e agir mobilizados. Os procedimentos utilizados por uma pesquisa podem reforçar frustrações e dificuldades, podem mobilizar experiências que não são compartilhadas e, ao mantê-las isoladas, não contribuem para que sejam encarnadas em modos de ação mais potentes. Mas também é possível construir dispositivos que reconheçam a experiência do outro, que contribuam para a emergência de novas subjetividades, de novas possibilidades de ação e de conexão com o mundo. Na pesquisa citada acima, por exemplo, há uma aposta na potência inventiva das variações dos modos de existir sem ver (MORAES; KASTRUP, 2010). Não se trata de negar que haja limitações impostas pela ausência da visão, mas sim de fazer existir a variação, de conferir um estatuto de positividade a essa dimensão de variação, de forma que as linhas que separam eficiência e deficiência sejam nuançadas e embaralhadas.

Essa aposta guia a construção e manejo dos dispositivos da pesquisa, guia a forma como são estabelecidos e gerenciados os vínculos com os participantes. A construção de tais vínculos envolve criar condições para uma criação coletiva e partilhada de sentido, o que implica não só a possibilidade de colocação das questões que são próprias dos diversos atores envolvidos, mas também a abertura aos efeitos dos encontros que ali se estabelecem, pois é certo que os pesquisadores e os participantes possuem interesses, concepções e avaliações diferentes quanto ao que tem lugar no processo da pesquisa. Isso, contudo, não constitui um obstáculo à realização do trabalho, nem significa que um bom encaminhamento se daria na direção da produção de um sentido único. Trata-se de fazer multiplicar os pontos de conexão, criar uma zona de "inter-esse" (STENGERS, 1993, DESPRET, 2004) na qual essas diferenças compareçam e sejam articuladas. O que se busca é a constituição de um plano de experiência compartilhada, em que as singularidades dos encontros que se fazem presentes no campo concorram para multiplicar as possibilidades de conexões entre sujeitos e mundos. Entretanto, para isso não basta apenas um suporte teórico ou conceitual. Tampouco isso se realiza simplesmente por meio da formalização de um contrato ou da instituição de regras.

É nesse sentido que visamos, neste texto, discutir a confiança como pista para o método da cartografia. A confiança, no sentido pragmático com o qual trabalhamos, ajuda-nos a discutir o aspecto ético da cartografia em sua conexão com o aspecto metodológico. O ethos da confiança tem o sentido de abertura ao plano da experiência e de aumento da potência de agir. A cartografia como método pressupõe uma descentralização nas práticas de pesquisa, em prol de um processo coletivo e compartilhado de produção de conhecimento. Em vez de um regime de suspeita em relação à experiência, no qual toda dimensão de vínculo é tratada sob a égide do controle e do juízo, a cartografia aposta na riqueza deste plano. Conta com a sua potência de criação, abrindo-se para ser articulada por ele. Eis o que encontramos na palavra confiança - con fiar - fiar com, tecer com, composição e criação com o outro/outrem. 
Como veremos, a confiança diz respeito tanto ao regime afetivo de articulação quanto à abertura para as transformações decorrentes dessa articulação. A questão da promoção e do manejo dos vínculos, tanto entre pesquisador e participantes, quanto entre todos esses envolvidos e as atividades próprias do processo da pesquisa, é tratada fora dos quadros de uma deliberação voluntária ou do cálculo de efeitos. ${ }^{2} \mathrm{O}$ texto é dividido em duas partes. Na primeira, destacamos na noção de confiança dois aspectos integrados: engajamento e indeterminação. A confiança é o que nos dispõe a agir a partir do vínculo com um plano da experiência anterior à determinação de si e do mundo. Essa disposição pressupõe um aumento na potência de agir, a partir da composição com o plano de forças (ESCÓSSIA; TEDESCO, 2009). Discutimos, então, como se dá o engajamento com base na indeterminação, o que contribui para pensar a produção da participação nas práticas de pesquisa. A aposta é de que a confiança na experiência implica a promoção de uma experiência compartilhada que amplia nossa potência de agir. Na segunda parte do texto analisamos a produção da confiança a partir dos dispositivos de pesquisa. Discutimos como esses dispositivos podem vir a incorporar e fomentar uma relação de confiança. Assim, esta comparece, ao mesmo tempo, como um meio e um fim da pesquisa.

\section{A CONFIAnÇa na EXPeriênCIA: O AUMEnto NA POTÊnCIA de AGIR}

Afirmar que a pesquisa se assenta na confiança na experiência significa que há confiança na potência dos encontros que se dão com o (e no) campo, no processo de pesquisa. Confiar na potência de um encontro não se confunde com a ideia de completude, identidade ou convergência de interesses e finalidades. Não se trata de confiar em um resultado específico. As alianças fundadas na confiança não se sustentam na identidade de um estado de coisas ou de representações de um futuro, mas em zonas de indeterminação que nos lançam em trajetórias inventivas.

Suely Rolnik (1994), ao discutir o filme Confiança (1990) de Hal Hartley, mostra como a confiança é indissociável do devir. A partir do trajeto dos personagens Mathew e Maria, cujas vidas estão à beira do abismo no momento em que se encontram, Hartley e Rolnik desenham um constante embate entre forças de homogeneização e forças de reação. As forças de homogeneização configuram o polo do senso comum, onde se "brinca de eternidade" e tudo aquilo que pode vir a ameaçar a uniformidade e a estabilidade do estado de coisas é visto como ameaça. Já as forças de reação constituem as linhas de fuga que continuamente irrompem produzindo fissuras no plano achatado do senso comum. Essas forças de reação podem se efetuar seja por meio de uma vontade de destruição, seja por uma potência de singularização. A vontade de destruição não leva senão à aniquilação, ao niilismo. É a potência de singularização que responde pela possibilidade de criação de novos modos de subjetivação. O que é interessante no filme de Hartley é exatamente como o encontro de Mathew e Maria opera uma transformação que faz com que estes consigam se entregar à queda de suas vidas no senso comum, que eles não mais sustentam, e dar passagem às forças de singularização que possibilitam a criação de novos territórios existenciais. 
No filme não sabemos o que acontecerá com a relação dos dois, mas sabemos o que o campo de confiança estabelecido entre eles propiciou, e é isso o que importa: a coragem da entrega à existência para além dos polos opostos de vontade de completude e vontade de destruição. A confiança é um momento em que as forças de heterogeneização estão por cima:

Amparar o outro na queda: não para evitar que caia, nem para que finja que a queda não existe ou tente anestesiar os seus efeitos, mas sim para que possa entregar-se ao caos e dele extrair uma nova existência. Amparar o outro na queda é confiar nessa potência, é desejar que ela se manifeste. Essa confiança fortalece, no outro e em si mesmo, a coragem da entrega (ROLNIK, 1994, p. 8).

É nesse sentido que valorizamos a concepção de confiança presente no pragmatismo de William James (2001). Em James a confiança é vital. Não remete às condições de âmbito pessoal necessárias para que se obtenha êxito. Não diz respeito nem mesmo propriamente ao êxito. Como chama a atenção Lapoujade (1997), para o pragmatismo jamesiano o problema da ação e da confiança não se coloca no nível das condições de sua eficácia, mas sim no plano da possibilidade de sua existência. Privilegiar o conceito de confiança, nesse sentido pragmático, implica tomar o problema da ação de um ponto de vista imanente, em que não é possível definir de antemão os limites, possibilidades e efeitos dessa ação. A confiança diz respeito à disponibilidade para agir quando os limites e possibilidades de ação excedem a capacidade de compreensão e conhecimento (LAPOUJADE, 1997). Não seria esse exatamente o ponto em que nos situamos quando envolvidos em um processo de pesquisa?

\begin{abstract}
É a indeterminação que faz com que tenhamos necessidade de confiança, mas é igualmente porque temos confiança que nos arriscamos no indeterminado. A confiança não consiste em realizar uma ação cujo sucesso é assegurado (previsão), mas em tentar uma ação cujo resultado é incerto (antecipação). [...] O sentimento de confiança faz da experiência um domínio de experimentação. Ele é a condição de todo ato de criação (LAPOUJADE, 1997, p. 108).
\end{abstract}

Uma crise de confiança implica o desligamento dos vínculos, uma atitude de inércia e algo como "a morte da sensibilidade". O mundo deixa de significar, nada mais afeta, de forma que toda ação se mostra inócua. É a confiança que nos liga ao mundo, por isso a crise de confiança resulta no niilismo. A suspensão da crença em "um" mundo, mantida a confiança, não é vivida como o fim de todo e qualquer mundo (como no niilismo). Com a confiança a nossa potência de agir excede aquilo que conhecemos, e, por isso, ela é condição de todo ato de criação (LAPOUJADE, 1997). Ela é fundamental na criação de novas conexões com a diferença, com aquilo que não experimentamos clara e explicitamente, mas virtualmente. A confiança diz respeito a uma dimensão intensiva da consciência em que essa encontra seus limites, em uma zona de permeabilidade entre interior 
e exterior. Promove, assim, a atualização de forças inéditas no nosso campo de consciência, e, ao mesmo tempo, novas possibilidades de ação. "Ter confiança é adotar um acordo tácito. Tácito porque, de certa maneira, a ideia não promete nada: não se sabe de antemão isso que o acordo dará" (LAPOUJADE, 1997, p. 115). Falar em "acordo" ou "ideia" não significa aqui um retorno a uma ordem reflexiva e voluntária, envolvendo sujeitos de razão.

Isso que Lapoujade chama de acordo tácito, a nosso ver, aponta para algo que é da ordem de uma afecção que marca e guia o engajamento em uma experiência para além de qualquer expectativa determinada. Trata-se de um "levar adiante em consonância com", ter a sensibilidade e a ação alinhadas a séries de signos que se oferecem em um plano da experiência que não é propriedade de um sujeito, mas se ancoram em um plano comum.

A noção de sintonia de Daniel Stern (1992) ajuda-nos a compreender esse engajamento na experiência a partir de um plano comum e indeterminado. A sintonia responde pela instauração de um campo específico de realidade que dá sentido à experiência de si e de outrem. É a partir da relação mãe-bebê que Stern formula o conceito de sintonia. Entretanto, os resultados de seu estudo não se restringem apenas aos bebês, pois aqui não se trata de fases do desenvolvimento, mas de formações subjetivas que permanecem coexistentes ao longo de toda a vida. O estudo dessa relação é relevante porque diz respeito a uma forma de comunicação que é anterior à construção de uma identidade e de uma ordem racional e voluntária. A sintonia, ou compartilhamento de estados afetivos, ocorre largamente sem ser notada, fora da consciência reflexiva. Para além dos afetos categóricos (alegria, tristeza, raiva etc.), percebemos afetos de vitalidade, qualidades que se expressam nos menores gestos cotidianos, no modo como se faz qualquer coisa. Essas qualidades são percebidas em termos dinâmicos e cinéticos, a partir de um plano de percepção amodal.

Toda experiência possui duas dimensões: uma modal (que pode ser gustativa, tátil, olfativa, visual ou auditiva) e outra amodal, que antecede a diferenciação dos sentidos (ritmos, velocidades, intensidades e formas). ${ }^{3}$ Esse plano amodal comunica forças e é pré-reflexivo, podendo ser apreendido nos diversos modos sensoriais. Assim, uma informação recebida numa modalidade sensorial (como, por exemplo, o tato), pode ser traduzida em outra (visão). As percepções amodais, ao serem "preenchidas" por afetos de vitalidade, ajudam a integrar experiências. Cada processo de relacionar eventos constitui experiências emergentes distintas. O compartilhamento de experiências ocorre quando a percepção amodal atravessa e integra diversos sentidos, construindo uma experiência singular de mundo (emergência de eu/outro) a partir de um plano comum. Esses processos de sintonia, na medida em que criam um plano de experiência comum, permitem que haja confiança para agir no mundo.

O conceito de amodal ajuda-nos a entender um regime de articulação dos corpos que não é de ordem identitária ou representacional. A sintonia do afeto, ao aceder a esse plano comum, pode expressar uma comunhão ou (possuir uma função de) comunicação. Quais são os atos e processos que nos permitem saber 
que um canal de comunicação se abriu? Num certo nível da experiência podemos experimentar, para além das pessoas e coisas determinadas, propriedades que transbordam a elas, o que cria o sentido de pertencimento e de viver junto uma experiência afetiva que perpassa os envolvidos e os engaja a partir do plano processual da realidade. Sentimos que podemos nos lançar no mundo porque dispomos de um plano comum que habitamos.

Isto significa que a confiança não é um sentimento pessoal, mas sim uma ciência (awareness) que se ancora em um plano comum (amodal) de experiência. Por isso podemos falar em senso de confiança. A nosso ver, o senso de confiança emerge com a sintonia afetiva, como processo de contração de si e do mundo, tal como o senso de si emergente descrito por Stern (1992). Este pressupõe uma percepção direta e "global" de uma organização mínima que me articula, mas que ainda não pode ser localizada em uma interioridade ou em uma exterioridade, nem definida segundo as estruturas e esquemas da experiência do adulto. A noção de senso é importante, pois aponta para o caráter ao mesmo tempo pré-reflexivo e relacional da experiência.

Pode-se perceber essa situação de conquista da confiança com base na sintonia em um projeto realizado em uma escola especializada para deficientes visuais. ${ }^{4} \mathrm{O}$ trabalho apostava na possibilidade de construir entre os familiares responsáveis pelas crianças que frequentavam essa escola - um grupo de partilha de experiências que ajudasse no enfrentamento dos desafios encontrados por eles. A maioria das mães não deixa as crianças, mas fica no pátio da escola, ou na "sala das mães" durante as aulas. Embora o grupo tenha tido uma boa adesão inicial, aos poucos foi-se dando certo esvaziamento. Após alguns encontros que nos pareceram intensos e produtivos, alternaram-se outros em que poucos compareceram. Algumas mães se queixavam: "aqui nada dá certo, no início todos se animam e logo depois desistem". Perante essas falas, decidimos perseverar e, sem nos retirar do campo, frustradas por uma experiência que "não estava dando muito certo", resolvemos entender melhor um discurso que circulava, de forma não muito explícita, de que o pátio era local de fofocas e mexericos. Atentamos para a formação de pequenos grupos "rivais". Percebemos que os locais nos bancos do pátio eram demarcados, assim como a "sala das mães". Costumávamos nos encontrar com as mesmas mães nos mesmos bancos ou juntas no mesmo grupo. A construção de laços de confiança mostrava-se como um desafio e nos forçava a repensar nosso dispositivo. $\mathrm{O}$ modo como o grupo operava talvez não estivesse contribuindo para a formação do senso de confiança, e, por conseguinte, do engajamento no trabalho proposto. Ao iniciar o encontro nos sentávamos em roda esperando que a fala surgisse espontaneamente, o que às vezes causava certo clima de tensão e desconforto no grupo. Apesar de não ser essa a nossa proposta, quase sempre as falas que circulavam eram individualizadas, cada uma relatando sua tragédia pessoal, favorecendo um discurso intimista de sofrimento e vitimização. Após observar todas as questões, que acreditávamos estar dificultando a realização de nosso trabalho, decidimos modificar o dispositivo trazendo toda semana um disparador diferente. 
Textos, poesias, filmes, músicas e trabalhos corporais tinham o objetivo de fazer circular e descentralizar a fala. Partia-se de um território comum de afetação em que iam se produzindo diversas bifurcações e desvios.

Apresentamos inicialmente o filme "Vermelho como o Céu" (Cristiano Bortone, Itália, 2006). O debate foi enriquecedor como pudemos constatar em vários encontros posteriores em que o filme foi relembrado e trazido à baila para tratar de assuntos presentes na vida daquelas mães. Os textos "Vista cansada" de Otto Lara Resende, e "Eu sei, mas não devia" de Marina Colasanti, assim como o filme "O milagre de Anne Sullivan" (Arthur Penn, EUA, 1962) são exemplos de disparadores que se destacaram ao produzir problematizações que circularam entre todos.

Procurávamos escolher os disparadores levando em conta as questões que com frequência emergiam no grupo, com o objetivo de produzir deslocamentos de lugares instituídos e cristalizados. Mas, ao mesmo tempo, não havia um foco previamente estabelecido, cada encontro estava aberto ao inesperado, ao componente afetivo que, surgindo na experiência com cada obra, possibilitaria que se construíssem outros olhares, propiciadores da construção de novas subjetividades.

A maneira como o grupo se entregava à experiência compartilhada produzia apropriações e questões distintas, favorecendo ,então, a construção de uma grupalidade. Os disparadores produziam efeitos que podiam apresentar um grau de perturbação maior ou menor, convocando mais ou menos a fala. O que nos chama a atenção é que o discurso que passa a circular no pátio não é mais "fulaninha chorou", mas "como foi bom aquele filme! Temos como conseguir uma cópia?" Tivemos indício disso na fala de uma das mães quando, no dia do encerramento, ao avaliarmos o novo modo de funcionamento do grupo, ela comenta que naquele semestre havia chorado, rido e que, mesmo assim, não houve comentários sobre isso nos corredores. Quando encontrávamos familiares que não haviam comparecido ao encontro, eles comentavam a respeito das atividades realizadas. Assim, os participantes foram-se apropriando mais do grupo, o clima de expectativa foi dando lugar a um clima de maior descontração e leveza. Os familiares ficavam mais à vontade para se colocar, compartilhando alegrias, questões cotidianas e podendo também acolher o sofrimento.

Outro efeito importante a ser destacado: o lugar hierarquizado de especialistas foi sendo diluído, pois os pesquisadores passavam a ser considerados como parte integrante, mesmo que ocupando um lugar diferenciado. Observamos isso na fala de uma das integrantes mais antigas, quando, ao apresentarmos o grupo para algumas mães que chegavam pela primeira vez, ela brinca: "elas são da psicologia, mas não ficam analisando ninguém não, nós que analisamos elas". Essa aparente inversão de papéis aponta para uma mudança de perspectiva em relação a certo imaginário do lugar que o psicólogo ocupa e que seria causa de constrangimento para alguns. O espaço do pátio passa a compor com o espaço do grupo, ocorrendo uma ampliação de seus efeitos dentro da escola (numa dinâmica instituinte de partilha e troca, mais do que a instituída como o lugar da fofoca etc.). Como efeito dessa nova configuração, as discussões tornavam-se mais coletivizadas e fluidas, indicando a emergência da confiança dentro e para além do grupo. 
No momento da apreciação estética, um plano comum foi ativado e a sintonia afetiva pôde então ocorrer. Seguindo Deleuze e Guattari (1997) podemos dizer que a obra de arte - bloco de sensações, composto por perceptos e afetos - existe em si e por si, e excede a qualquer vivido. Os afetos, no sentido explicitado aqui, não se confundem com sentimentos, pois não são pessoais, e os perceptos não são percepções, já que transbordam os que são atravessados por ela. Esses afetos não pessoais atravessam a todos, construindo uma experiência compartilhada, em sintonia. Nesse trabalho de pesquisa o disparador artístico possibilitou acionar um plano de sensações, que é amodal. As mães falam então de suas experiências a partir de outro lugar, perspectiva que não mais as isola, tornando-as parte de uma experiência comum. A sintonia permite, então, a emergência da confiança.

A promoção da confiança, portanto, tem como desafio construir dispositivos que ensejem a sintonia, ou um regime de comunicação assentado fundamentalmente no plano das forças. $\mathrm{O}$ acesso à organização emergente da experiência promove senso de confiança, assim como o engajamento que o pressupõe. Isto é importante para fomentar a participação em processos de produção coletiva de conhecimento, como é o caso nas pesquisas cartográficas. Não se trata apenas da utilização de um determinado dispositivo, mas também de como manejá-lo de forma a criar uma zona de "inter-esse" que vincule e articule pesquisadores, pesquisados e o campo de pesquisa. A aposta é de que a produção de conhecimento a partir da instauração desse plano de experiência comum é acompanhada da produção coletiva de novas condições de existência. Este é o tópico para o qual nos voltaremos agora.

\section{CONFIANÇA E RECALCITRÂNCIA: O REGIME DE CONTRATAÇÃo}

A etnógrafa Jeanne Favret-Saada (2005), ao empreender um trabalho sobre feitiçaria, em 1968 no Bocage francês, deparou-se com uma dificuldade significativa para abrir um canal de comunicação com o campo. A população local havia tido experiências anteriores com pesquisadores que desacreditavam a prática da feitiçaria e desqualificavam a palavra nativa. As práticas tradicionais dos etnógrafos, visando não contaminar o objeto a ser estudado, eram cuidadosas e procuravam preservar a distinção entre "eles", os pesquisados (os atrasados culturalmente), e "nós", os cientistas (os donos do saber). A partir de um histórico de contatos anteriores com pesquisas dessa natureza, os camponeses do Bocage começaram a se recusar a participar de pesquisas, pois sabiam que acabariam na condição de atrasados e ignorantes. Favret-Saada deparou-se, então, com a recalcitrância da população local.

Segundo Latour (2000), a recalcitrância ou resistência é a capacidade que os objetos têm de discordar a respeito daquilo que é dito deles, levantando novas questões, tensionando os saberes e as práticas. Nas pesquisas com humanos, a relação com a recalcitrância não é apenas uma questão epistemológica, relativa aos modos de conhecer, mas também ética, relativa ao reconhecimento e valorização da experiência do outro. É o que vemos nesse caso da investigação de Favret-Saada, assim como no caso da pesquisa com cegos citada na Introdução. Para que a recalcitrância não seja vivida como ruptura ou quebra da relação é 
preciso confiar, qualificando a resistência mais como um vetor de diferenciação, um convite para criar novas possibilidades. O que permite que os atores envolvidos na pesquisa reposicionem um em relação ao outro. A questão da confiança nos permite integrar os dois aspectos, o ético e o epistemológico, apostando, ao mesmo tempo, em novas práticas de conhecimento e novos modos de existir.

Favret-Saada (2005) aproximou-se do campo, buscou ouvir o que essas vozes campesinas recalcitrantes estavam querendo dizer: não era possível para eles falar sobre feitiço para quem nunca o experimentou. Para realizar a pesquisa, ela não teve alternativa senão "se deixar pegar" pela experiência de ser enfeitiçada. Ela apostou na abertura de um canal de comunicação involuntária e desprovida de intencionalidade, em sintonia do afeto. Apenas a partir desse momento em que ela "se deixou afetar" foi possível iniciar seu trabalho, construindo com o campo uma relação de confiança. Ao se despir do lugar de "dona do saber" e se colocar como parceira, lateralizando com o campo, foi possível construir um plano de experiência comum, que potencializou não apenas sua pesquisa, permitindo que um canal de comunicação fosse aberto, mas também permitindo que o campo se expressasse de forma plena.

Por outro lado, dispositivos de pesquisa fundados em um modelo do conhecimento como representação, cujo objetivo é ter uma relação de hierarquia (verticalidade) entre pesquisador e pesquisado, não contribuem para fomentar a confiança, o envolvimento do pesquisador e o engajamento do participante. Nesses dispositivos há um constante esforço de purificação que permitiria ver e distinguir em qualquer fenômeno aquilo que pertence unicamente ao sujeito do conhecimento e aquilo que pertence à realidade conhecida (CHERTOK; STENGERS, 1990; STENGERS, 1989, 1993). O esforço de purificação requer por parte do pesquisador uma constante vigilância ajuizadora, que separaria aquilo que é da ordem da realidade do fenômeno e aquilo que é unicamente da ordem das aparências subjetivas, da crença e do interesse. Dessa forma, a nosso ver, todo modus operandi da pesquisa é marcado por uma relação de desconfiança no que diz respeito aos vínculos produzidos com (e no) campo.

Vinciane Despret (2011a; 2011b) analisa dois procedimentos comuns em pesquisas que operam segundo esse modus operandi judicativo e purificador: o anonimato e o chamado pacto da dupla ignorância. $\mathrm{O}$ anonimato tem por fim garantir a integridade do participante e a legitimidade de sua participação. Ao apagar o nome, coloca-se o participante sob o registro do "não importa quem" (quicon$q u e$ ), colocando em cena sujeitos abstratos e genéricos. Segundo ela, o anonimato, paradoxalmente, cria uma identidade: apagando o nome é que se cria a posição de "sujeito" da pesquisa; alvo passivo das ações do pesquisador. Já o pacto da dupla ignorância diz respeito a dois aspectos articulados: a manutenção em segredo por parte do pesquisador dos objetivos e hipóteses da pesquisa para evitar qualquer influência sobre o participante; e o fato de este por sua vez não dizer o que sabe ou quais são suas hipóteses sobre o que está em jogo, devido à autoridade do pesquisador ou porque teme que isso invalide sua participação. Dessa forma, nem o pesquisador, nem o participante têm verdadeiramente interesse em dizer ou saber o que está em jogo, pois parte-se do pressuposto de que isso invalidaria a experiência. 
O que Despret aponta, contudo, é que essas práticas garantem (supostamente) a objetividade, colocando em cena corpos abstratos e desinteressados, corpos dóceis. "Elas estão sempre correndo o risco de colocarem as pessoas em situações em que elas têm pouca chance de serem interessantes, e pouca chance de ficarem interessadas" (DESPRET, 2011a, p. 20). Dependendo das perguntas feitas, do modo como são formuladas, e do modo como os participantes as escutam, estes podem ser compelidos à docilidade, a obedecer ao que lhes é demandado. E mesmo quando eles têm algo a dizer, muitas vezes o dispositivo não lhes dá oportunidade, como no caso do pacto da dupla ignorância. Com base nos trabalhos de Chertok e Stengers (1990) e Despret (2004), buscamos avançar e pensamos que a docilidade é efeito de uma relação de desconfiança que recalca as singularidades ou afetos mobilizados no processo de pesquisa. Esse plano afetivo ou comum da experiência deve ser recalcado para assegurar a separação entre sujeito e objeto permitindo, assim, que o fato científico (purificado) se constitua como tal. Mas ele também contribui para manter o isolamento do participante, posição do sujeito anônimo, não dando margem para a criação de articulações (LATOUR, 2007), para que o participante se aproprie ou encarne o território da pesquisa. Dessa forma, esse recalque impede, ao mesmo tempo, que o sujeito anônimo (sujeitado) da pesquisa se torne, de fato, um participante, e que o pesquisador desinteressado se torne alguém envolvido no processo, interessado nos seus efeitos.

Como contraponto a esse recalque, apostamos em práticas de pesquisa nas quais a produção de conhecimento se faz de forma descentralizada ou coletiva. Vejamos o exemplo de uma pesquisa realizada na Universidade Federal Fluminense (EIRADO et al, 2006; EIRADO et al, 2010), na qual se investigou o fenômeno das falsas lembranças tal como formulado por Loftus e Hoffman (1989) e Schacter (2003). A pesquisa foi realizada em duas etapas. Na primeira, os participantes realizavam um protocolo experimental. ${ }^{5} \mathrm{Na}$ segunda, realizada no intervalo de uma semana, retornavam para uma entrevista acerca da experiência do protocolo. Na primeira fase, as pessoas não eram informadas sobre o objetivo da pesquisa, não lhes era dito que se tratava de uma pesquisa sobre memória, elas eram convidadas a participar de uma investigação sobre percepção visual e compreensão escrita. Nessa fase, os participantes limitavam-se a responder um questionário sobre os objetos que tinham visto nos slides anteriormente apresentados. Contudo, na segunda etapa, durante a conversa da entrevista, os participantes demonstravam construir hipóteses corretas a respeito do experimento, indicando a ocorrência do pacto da dupla ignorância durante a realização do protocolo. Demonstravam interesse em algumas etapas do protocolo (especialmente os slides) e diziam não terem gostado de outras (especialmente as tarefas distratoras). E, sobretudo, mostravam-se animados em poder compartilhar conosco suas hipóteses e ideias a respeito do protocolo. A entrevista acontecia numa atitude de "disponibilidade aos eventos", como define Despret (2004), dando oportunidade ao entrevistado de nos mostrar quais as perguntas mais interessantes, de resistir e objetar às questões propostas, e responder nos seus próprios termos. 
A entrevista não estava voltada para a adequação das respostas dos participantes ao protocolo anteriormente aplicado, mas sim para a experiência do lembrar; ela visava uma investigação cartográfica (RENAULT; PASSOS; EIRADO, no prelo). $\mathrm{O}$ entrevistador não se colocava numa posição hierárquica de quem dirige, mas seguia linhas de conversa que eram traçadas conjuntamente com o entrevistado. O manejo não diretivo na entrevista era voltado para que ambos, entrevistador e entrevistado, confiassem na experiência, de forma que a própria entrevista fosse guiada (articulada) por um plano comum. Muitas vezes, o participante e o entrevistador chegam armados de preconcepções a respeito do que é uma entrevista, do que se quer ouvir, o que se deve ou não deve falar. Mas, na medida em que o próprio dispositivo é voltado para fomentar abertura ao plano de forças, ensejando que entrevistado e entrevistador possam se vincular e compor com este plano, o dispositivo propicia que nos disponhamos a agir a partir da indeterminação. A sintonia constituída nesse caso permite que ambos sintam que a singularidade em sua experiência é compartilhável, e que confiem.

A confiança na relação entre entrevistador e entrevistado, nessa pesquisa, não visava estabelecer condições favoráveis para uma melhor coleta de informações; não era esse o objetivo da entrevista (RENAULT; PASSOS; EIRADO, no prelo). Ela favorecia a emergência de uma relação criativa com a experiência, expressa em algumas falas e atitudes que, para nós, eram índices de aumento da potência de agir. O entrevistado inicialmente vivia a entrevista como uma situação de teste, o que gerava falas em que ele procurava justificar a (suposta) inadequação de sua lembrança: "não consigo me lembrar!", "minha memória não é boa!". Porém, o manejo do entrevistador possibilitava a contemplação do plano emergente da experiência, que era acompanhada de falas que expressavam espanto, surpresa, assim como descontração e entusiasmo diante da criação de novas possibilidades de ação, correspondentes a configurações inéditas (ainda que indeterminadas) de si e do mundo. Percebíamos um engajamento crescente do entrevistado com a construção da confiança, trazendo novas lembranças e novas questões com satisfação. No entrevistador, notamos a condução menos armada e mais em sintonia com a experiência, abrindo-se para redefinir as questões e os encaminhamentos da entrevista. $\mathrm{O}$ manejo acolhia diferentes perspectivas, o que favorecia ao entrevistado sentir-se pertencente e corresponsável, compartilhando o protagonismo na entrevista. Dessa forma, durante a entrevista, o "sujeito anônimo" (do protocolo experimental) transformava-se em "participante".

A produção da confiança, portanto, requer dispositivos coletivos de pesquisa; não se trata de apelar para o imperativo: confiem! Os dispositivos precisam cultivar a confiança, pois confiança demanda tempo, temporalidade ${ }^{6}$ na qual se estabelece a sintonia afetiva e o engajamento que nela se baseia. O que põe em questão a regulação dos vínculos na pesquisa, assim como a própria definição do seu domínio, isto é, de suas regras e acordos.

Gerenciar a questão dos vínculos na pesquisa unicamente a partir do contrato, como é feito tradicionalmente, traz em si a concepção de que se poderia abrir mão de toda a dimensão processual de cultivo e contração desses vínculos. Se estes são baseados apenas em termos preestabelecidos, não há margem para que 
se façam articulações com as recalcitrâncias que emergem ao longo do processo. A característica essencial do contrato é a reabsorção do múltiplo na unidade/ totalidade do contrato. Esta opera, assim, uma limitação da potência. "A unidade do acordo não reabsorve a multiplicidade dos modos de se ligar a ele, nem por consequência a distância entre os indivíduos" (LAPOUJADE, 1997, p. 145). Essa discussão torna-se ainda mais importante quando pensamos em pesquisas nas quais os participantes se encontram em situações de periculosidade, dominação ou carência (como usuários de drogas, presos, usuários da rede de saúde mental, trabalhadores clandestinos etc.) e que, por isso, trazem impedimentos na assinatura de um contrato, como o termo de consentimento livre e esclarecido (TCLE).

Um problema dessa ordem aconteceu na pesquisa para adaptação do guia de gestão autônoma da medicação (GAM). ${ }^{7}$ No momento da apresentação do TCLE para os participantes, a pesquisa se viu diante da recalcitrância deles. Tradicionalmente, a assinatura do TCLE é vista como condição de possibilidade para iniciar a pesquisa, e para que os participantes possam, de fato, participar. No entanto, a pesquisa GAM deparou-se com o fato de que alguns convidados que se interessaram em participar não aceitaram assinar o TCLE no momento inicial de pactuação da pesquisa. Para o pesquisador caberia, então, descartar aquele participante e prosseguir com a pesquisa? Se o pesquisador confia, ele reconhece a legitimidade dessa resistência, acolhendo essa não assinatura como uma questão de pesquisa. Ele acolhe e se dispõe a agir com essa singularidade.

A pesquisa GAM incluiu o protagonismo do participante já nesse momento de assinatura do TCLE. Os pesquisadores não recusaram a participação daqueles que não assinaram o TCLE, eles se propuseram a negociar a questão da assinatura ao longo dos encontros da pesquisa, de forma que foi dada a possibilidade de eles assinarem o TCLE nos encontros subsequentes. Apostaram que o contrato resulta da confiança, isto é, da construção da confiança por parte dos participantes na experiência da pesquisa. Com base na confiança, o que nos une é um comum indeterminado, muito mais do que cláusulas determinadas. A pesquisa GAM não abriu mão do contrato, mas buscou pensá-lo intimamente articulado (em sintonia) à dimensão processual e coletiva que configura as bases e termos de sua constituição. Ela preferiu, portanto, operar em um regime de "contratação".

A contratação enseja que o participante se articule à experiência da pesquisa, coletiva e progressivamente. A mera assinatura de um contrato como o TCLE não assegura a participação. Observou-se na pesquisa GAM que muitos participantes, mesmo quando assinavam o TCLE, o faziam de modo nada esclarecido, parecendo mais um ato de obediência do que de consentimento. A construção da confiança e a conquista do engajamento se fizeram concomitantemente ao cultivo de uma experiência compartilhada de pesquisa.

Operando em regime de contratação, a pesquisa cultiva a participação em um processo ele mesmo participativo. Acolher as recalcitrâncias do objeto não significa aceitação "literal". Trata-se fundamentalmente de um "fazer junto", "em parceria", ou em sintonia. Se para uma pesquisa experimental, não compartilhar as questões e hipóteses é uma regra dada, para uma pesquisa que opera em regime 
de contratação essa regra deve ser continuamente definida em sintonia com as singularidades do campo. A contratação pressupõe a pesquisa como um evento em aberto, que não está completamente determinado, e para o qual alguns encaminhamentos só serão definidos de forma compartilhada com os participantes, gerando experiências de pertencimento e cultivando a confiança.

\section{CONFIANÇA COMO MEIO E FIM DA PESQUiSA}

O ethos da confiança, no sentido pragmático com o qual trabalhamos, possibilita performatizar e ressaltar a inseparabilidade dos aspectos éticos e metodológicos na pesquisa cartográfica. A construção do dispositivo de pesquisa no método cartográfico tem como objetivo operar movimentos de alterização que abram caminho para redistribuições e novas configurações nas capacidades de ação e intervenção. Isso é importante não só no que diz respeito aos resultados da pesquisa, mas também (indissociavelmente) no que concerne ao próprio processo de realização desta. Os participantes da pesquisa não são apenas o alvo passivo das intervenções do pesquisador. A mudança de nomenclatura, já que falamos em participante e não mais em sujeito (anônimo) de pesquisa, não é gratuita, pois implica que o dispositivo com o qual se trabalha abra espaço para que este possa indicar quais as questões importantes a serem colocadas para ele, podendo, então, assumir um lugar de coautoria na produção de conhecimento. Dessa forma, o encaminhamento dos problemas trabalhados deve responder não só aos interesses do pesquisador, mas também ser capaz de tornar os participantes interessados e confiantes no processo, permitindo que assumam voz e participação.

Por isso, o regime de contratação é uma alternativa (ao contrato) interessante para pensarmos o manejo dos vínculos na pesquisa cartográfica. Ensejando não mais um dispositivo que, sob o preceito de resguardar a objetividade e a legitimidade do conhecimento, coloque o participante na condição de sujeito ingênuo, no registro da docilidade, mas sim um dispositivo que permita a emergência de uma participação efetiva, na qual o participante sinta que sua singularidade e a diferença que ela traz possa ser compartilhada e levada adiante. Comportar a diferença e levar essas singularidades compartilhadas adiante é dar lugar à indeterminação, trabalhando fora de uma lógica de antecipação dos efeitos, segundo a qual as formas já constituídas determinam o que se pode fazer e o alcance dessas ações. A pesquisa cartográfica opera confiando na potência dos encontros estabelecidos no processo de pesquisar.

Por isso, podemos dizer que a confiança comparece como meio e fim da pesquisa. Meio porque ela responde pelo engajamento com base em uma experiência compartilhada. E fim porque esse engajamento ganha sentido ampliando a potência de criação coletiva de territórios existenciais. Como vimos com as mães de deficientes visuais ao resignificarem o grupo de apoio e se apropriarem dele, com o cultivo do protagonismo compartilhado na entrevista e com a contratação na pesquisa GAM. Ressalta-se, aqui, o caráter de intervenção da pesquisa cartográfica, já que a instauração desse plano de experiência compartilhada é indissociável da produção coletiva de novas condições de existência. O senso de confiança mo- 
bilizado no próprio processo da pesquisa coloca-se também como produto desse processo. Os encontros ali produzidos resgatam a confiança no mundo, no fato de que algo pode vir a acontecer. Por entre as formas constituídas se insinuam frentes de indeterminação e o mundo se coloca novamente como matéria a ser trabalhada, como fonte de novas possibilidades de existência, convocando-nos, assim, a agir.

\section{Notas}

${ }^{1}$ Projeto de pesquisa "Atenção e invenção na produção coletiva de imagens" (CNPQ), coordenado pela Professora Virginia Kastrup (Universidade Federal do Rio de Janeiro).

${ }^{2}$ Distanciamo-nos aqui de leituras sociológicas que pensam a confiança como sendo da ordem das capacidades reflexivas do sujeito, responsáveis pelos cálculos cognitivos apropriados para a tomada de decisões. Cf. Salém (2006).

${ }^{3}$ A forma não significa a mesma aparência externa, mas algum aspecto espacial de um comportamento que pode ser abstraído e remodelado em um ato diferente, como por exemplo, mexer com a cabeça para cima e para baixo na mesma sequência de um determinado ritmo experimentado conjuntamente.

${ }^{4} \mathrm{O}$ projeto, intitulado "Dispositivo Clínico-grupal: uma abordagem transdisciplinar", consiste na realização de uma pesquisa-intervenção sobre métodos e estratégias clínico-grupais. Esse projeto vem sendo realizado no Instituto Benjamin Constant (IBC) desde agosto de 2010, funcionando como experiência de estágio para alunos em formação de psicologia na Divisão de Psicologia Aplicada (DPA) da Universidade Federal do Rio de Janeiro (UFRJ), a partir de um convênio estabelecido entre o IBC e a UFRJ.

${ }^{5} \mathrm{O}$ protocolo era baseado no modelo proposto por Belli (1989) e consistia em três etapas. Na primeira, os participantes assistiam uma apresentação de slides, cujas imagens contavam a história de um encontro entre amigos num apartamento. Em seguida, eles resolviam problemas lógicos (tarefa distratora). Na segunda etapa, era apresentada a mesma história numa narrativa, onde alguns elementos estavam trocados. Havia, por exemplo, um relógio na parede que marcava nove horas, mas na narrativa constava que eram três horas. Novamente os participantes resolviam problemas lógicos. Então, eles respondiam a um questionário acerca do que tinham visto nos slides. O objetivo do protocolo experimental era produzir falsas lembranças, que seriam detectadas no questionário.

${ }^{6}$ Pensamos em temporalidade como duração, no sentido bergsoniano (BERGSON, 2006). Não é tempo cronológico; às vezes em um breve contato dá-se uma sintonia. Com base na leitura deleuziana (DELEUZE, 1998) de Hume, podemos também usar o conceito de contração, a confiança é contraída em uma síntese passiva do tempo.

${ }^{7}$ Trata-se da pesquisa "Autonomia e direitos humanos na perspectiva em primeira pessoa de técnicos e usuários em serviços de saúde mental: a experiência da Gestão Autônoma da Medicação (GAM)", realizada num centro de atenção psicossocial (CAPS) da cidade do Rio de Janeiro e articulada com o projeto multicêntrico UNICAMP-UFF-UFRJ-UFRGS "Pesquisa avaliativa de saúde mental: instrumentos para a qualificação da utilização de psicofármacos e formação de recursos humanos" (ONOCKO CAMPOS et al., 2012).

\section{REFERÊNCIAS}

BELLI, R. Influences of misleading postevent information: misinformation interference and acceptance. Journal of Experimental Psychology: General. v. 118, n. 1, p. 72-85, Mar. 1989.

BERGSON, H. Matéria e Memória. São Paulo: Martins Fontes, 2006.

CHERTOK, L; STENGERS, I. O coração e a razão: a hipnose de Lavoisier a Lacan. Rio de Janeiro: J. Zahar, 1990. 
COLASANTI, M. Eu sei, mas não devia. Rio de Janeiro: Rocco, 1996. p. 9. Disponível em: <http://www.releituras.com/mcolasanti_eusei.asp>. Acesso em: 12 abr. 2013.

CONFIANÇA. Direção: Hal Hartley. USA: Channel Four Films; Republic Pictures (II); True Fiction Pictures; Zenith Entertainment, 1990. 1 DVD (107 min), comédia / drama.

DELEUZE, G. Conversações. Rio de Janeiro: Editora 34, 1992.

DELEUZE, G. Diferença e repetição. Rio de Janeiro: Graal, 1998.

DELEUZE, G.; GUATTARI, F. O que é a filosofia. São Paulo: Editora 34, 1997.

DESPRET, V. The body we care for: figures of antropo-zoo-genesis. Body and Society. [S.1.], v. 10, n. 2-3, p. 111-134, 2004.

DESPRET, V. Leitura etnopsicológica do segredo. Fractal: Revista de Psicologia, Niterói, v. 23, n. 1, p. 5-28, jan./abr. 2011a.

DESPRET, V. Os dispositivos experimentais. Fractal: Revista de Psicologia, Niterói, v. 23, n. 1, p. 43-58, jan./abr. 2011 b.

EIRADO, A. et al. Memória e alteridade: o problema das falsas lembranças. Mnemosine, Rio de Janeiro, v. 2, p. 75-86, 2006.

EIRADO, A. et al. Estratégias de pesquisa no estudo da cognição: o caso das falsas lembranças. Psicologia e Sociedade, v. 22, p. 84-94, 2010.

ESCÓSSIA, L.; TEDESCO, S. O coletivo de forças como plano da experiência cartográfica. In: PASSOS, E.; KASTRUP, V.; ESCÓSSIA, L. (Org.). Pistas do método da cartografia: pesquisa intervenção e produção de subjetividade. Porto Alegre: Sulina, 2009. p. 92-108.

FAVRET-SAADA, J. Ser afetado. Cadernos de Campo, [S.1.], n. 13, p. 155-161, 2005.

JAMES, W. A vontade de crer. São Paulo: Loyola, 2001.

LAPOUJADE, D. William James: empirisme et pragmatisme. Paris: Lês empêcheurs de penser en rond, 1997.

LATOUR, B. When things strike back: a possible contribution of science studies to the social sciences. British Journal of Sociology, [S.1.], v. 51, n. 1, Jan/Mar, p. 107-203, 2000. 
LATOUR, B. Como falar do corpo? A dimensão normativa dos estudos sobre a ciência. In: NUNES, J. A.; ROQUE, R. (Org.). Objetos impuros: experiências em estudos sociais da ciência. Porto: Afrontamento, 2007. p. 40-61.

LOFTUS, E.; HOFFMAN, H. G. Misinformation and memory: the creation of new memories. Journal of Experimental Psychology: General, v. 118, n. 1, p. 100-104, 1989.

O MILAGRE de Anne Sullivan. Direção: Arthur Penn. USA: Playfilms Productions, 1962. 1 DVD (98 min).

MORAES, M.; KASTRUP, V. (Org.). Exercícios de ver e não ver: arte e pesquisa COM pessoas com deficiência visual. Rio de Janeiro: NAU, 2010.

ONOCKO CAMPOS, R. et al. Adaptação multicêntrica de um guia para a Gestão Autônoma da Medicação. Interface: Comunicação, Saúde, Educação, [S.1.], v. 16, n. 43, p. 967-980, out./dez. 2012.

PASSOS, E; BENEVIDES DE BARROS, R. A cartografia como método de pesquisa-intervenção. In: PASSOS, E.; KASTRUP, V.; ESCÓSSIA, L. (Org.). Pistas do método da cartografia: pesquisa intervenção e produção de subjetividade. Porto Alegre: Sulina, 2009. p. 17-31.

PASSOS, E; EIRADO, A. Cartografia como dissolução do ponto de vista do observador. In: PASSOS, E.; KASTRUP, V.; ESCÓSSIA, L. (Org.). Pistas do método da cartografia: pesquisa intervenção e produção de subjetividade. Porto Alegre: Sulina, 2009. p. 109-130.

RENAULT, L; PASSOS, E; EIRADO, A. Da entrevista de explicitação à entrevista na pesquisa cartográfica. In: AMADOR, F. S.; BARROS, M. E. B.; FONSECA, T. M. G. (Org.). Clínicas do trabalho e paradigma estético. Porto Alegre: UFRGS. No prelo.

RESENDE, O. L. Vista cansada. Texto publicado no jornal "Folha de São Paulo", edição de 23 de fevereiro de 1992. Disponível em: <http://www.releituras.com/ olresende_vista.asp>. Acesso em: 12 abr. 2013.

ROLNIK, S. Hal Hartley e a ética da confiança. 1994. Disponível em: <http:// www.caosmose.net/suelyrolnik/pdf/confianca_corrigido.pdf $>$. Acesso em julho de 2011.

SALÉM, P. A gramática da quietude: um estudo sobre hábito e confiança na formação da identidade. 2006. Tese (Doutorado)-Instituto de Medicina Social da Universidade do Estado do Rio de Janeiro, Rio de Janeiro, 2006. 
SHACTER, D. Os sete pecados da memória: como a mente esquece e lembra. Rio de Janeiro: Rocco, 2003.

STENGERS, I. Quem tem medo da ciência?: Ciências e poderes. São Paulo: Siciliano, 1989.

STENGERS, I. A invenção das ciências modernas. São Paulo: Editora 34, 1993.

STERN, D. O mundo interpessoal do bebê: uma visão a partir da psicanálise e da psicologia do desenvolvimento. Porto Alegre: Artes Médicas, 1992.

VERMELHO como o céu. Direção: Cristiano Bortone. Itália: Orisa Produzioni; Ministero per i Beni e le Attività Culturali (MiBAC), 2006. 1 DVD (96 min), drama.

Recebido em: 05 de maio de 2013

Aceito em: 17 de julho de 2013 